\title{
In Vitro Dissolution Kinetics of Amlodipine Tablets Marketed in Russia Under Biowaiver Conditions
}

\author{
I. E. Shohin ${ }^{1,2}$, G. V. Ramenskaya ${ }^{1,2 *}$, \\ G. F. Vasilenko' ${ }^{2}$, E. A. Malashenko' ${ }^{1}$ \\ 'Sechenov's Moscow Medical Academy, Moscow, Russia \\ ${ }^{2}$ Scientific Center for Expertise of Medical Products, Moscow, Russia
}

\begin{abstract}
The current paper is devoted to in vitro dissolution kinetics studies of amlodipine tablets marketed in Russia under biowaiver conditions. Dissolution kinetics studies were carried out according to WHO Guidance. Dissolution profiles of test and reference (innovator) amlodipine tablets were considered equivalent.
\end{abstract}

\section{INTRODUCTION}

$\mathrm{O}$ ver the past three decades, dissolution testing has evolved into a powerful tool for characterizing the quality of oral pharmaceutical products. For some solid dosage forms containing active pharmaceutical ingredients with special properties, a comparative in vitro dissolution profile similarity can be used to establish equivalence of test with reference product. Such studies, used to approve equivalence other than through in vivo equivalence testing, are called "biowaiver" (1).

Amlodipine is a dihydropyridine calcium antagonist (calcium ion antagonist or slow-channel blocker) that inhibits the transmembrane influx of calcium ions into vascular smooth muscle and cardiac muscle. It is indicated for the treatment of hypertension, chronic stable angina, and confirmed or suspected vasospastic angina (2). The chemical name of amlodipine is 3-ethyl 5-methyl 2-[(2aminoethoxy)methyl]-4-(2-chlorophenyl)-6-methyl-1,4dihydropyridine-3,5-dicarboxylate. Its structure is shown in Figure 1.

\section{Solubility}

Amlodipine is described as slightly soluble in water in different Pharmacopoeias $(3,4)$. The experimental water solubility for amlodipine is $75.3 \mathrm{mg} / \mathrm{L}$ (5). The lowest solubility in the $\mathrm{pH}$ range from 1 to 6.8 at $37^{\circ} \mathrm{C}$ is $1 \mathrm{mg} / \mathrm{mL}$ (1). Within the gastrointestinal $\mathrm{pH}$ range, amlodipine is an ionized compound (weak base) (5). The $\mathrm{p} K_{\mathrm{a}}$ of amlodipine is about 8.6 at $25^{\circ} \mathrm{C}$ (5). Dosage form strength is expressed in $\mathrm{mg}$ of salt and is not equivalent to the free base. Amlodipine is listed in the WHO Model list of medicines as an antihypertensive medicine in a 5-mg tablet strength (6). Russia has Marketing Authorizations for amlodipine as an immediate-release dosage form in strengths of 2.5; , and $10 \mathrm{mg}$ (7). Thus the D/S ratio for the amlodipine WHO Model List of Essential Medicines dose ( $5 \mathrm{mg}$ ) at a

${ }^{*}$ Corresponding author.
$\mathrm{pH}$ range of $1.2-6.8$ is $5 \mathrm{~mL}$ and $10 \mathrm{~mL}$ for the highest dose marketed in Russia. Therefore, amlodipine is a "highly soluble" drug according to WHO Guidance (D/S ratio $\leq 250 \mathrm{~mL}$ ).

\section{Permeability}

When an active pharmaceutical ingredient is absorbed to an extent of $85 \%$ or more, it is considered "highly permeable." Amlodipine's absolute bioavailability is $60-65 \%$, but its permeability is classified as "high" due to metabolite excretion in urine (90-95\%). Taking amlodipine solubility and permeability into account, according to WHO Guidances, amlodipine is assigned to BCS Class I (1). Thus, amlodipine in vitro equivalence may be evaluated under biowaiver conditions for BCS Class I (1).

\section{MATERIALS AND METHODS \\ Chemicals}

Analytical grade concentrated hydrochloric acid, glacial acetic acid, potassium dihydrophosphate, disodium hydrophosphate dodecahydrate, and potassium chloride were used.<smiles>CCOC(=O)C1=C(COCCN)NC(C)=C(C(=O)OC)C1c1ccccc1Cl</smiles>

Figure 1. Structure of amlodipine. 
Table 1. Dissolution Amount ("rapidly dissolving", "very rapidly dissolving," or "not rapidly dissolving") for Evaluated Drugs

\begin{tabular}{|c|c|c|c|c|}
\hline \multirow[b]{2}{*}{ Medium } & \multicolumn{2}{|c|}{ Test Product } & \multicolumn{2}{|c|}{ Reference Product } \\
\hline & $\begin{array}{c}\text { \% dissolved } \\
(\bar{X}) \\
15 \text { min }\end{array}$ & $\begin{array}{c}\text { \% dissolved } \\
(\bar{X}) \\
30 \mathrm{~min}\end{array}$ & $\begin{array}{c}\text { \% dissolved } \\
(\bar{X}) \\
15 \mathrm{~min}\end{array}$ & $\begin{array}{c}\text { \% dissolved } \\
(\bar{X}) \\
30 \text { minv }\end{array}$ \\
\hline pH 1.2 & 91.99 & 92.72 & 97.70 & 97.36 \\
\hline pH 4.5 & 95.41 & 96.75 & 91.91 & 91.30 \\
\hline $\mathrm{pH} 6.8$ & 77.85 & 85.42 & 79.76 & 87.28 \\
\hline
\end{tabular}

Innovator amlodipine immediate-release tablets, used as reference product, and a generic version (test product) marketed in Russia were evaluated.

\section{Apparatus and Procedure}

All dissolution studies were performed using USP Apparatus 2 (Erweka DT 600, Frankfurt, Germany) at $75 \mathrm{rpm}$. Dissolution media were USP buffer solutions at pH 1.2 (hydrochloric acid solution), pH 4.5 (acetate buffer solution), and $\mathrm{pH} 6.8$ (phosphate buffer solution) at $37 \pm 0.5^{\circ} \mathrm{C}$. Dissolution media volume was $500 \mathrm{~mL}$. In all experiments, $5-\mathrm{mL}$ sample aliquots were withdrawn at 10 , $15,20,30$, and 45 min using micropipettes and immediately replaced with equal volumes of fresh medium at the same temperature to maintain constant total volume during the test. All samples were filtered through $0.45-\mu \mathrm{m}$ membrane filters. Drug release was assayed spectrophotometrically using a UV-vis spectrophotometer (Agilent 8453, Santa Clara, California, USA) at $239 \mathrm{~nm}$. Twelve tablets of each preparation were studied to obtain statistically significant results. Dissolution profile comparisons were made according to WHO Guidances (1). Statistical treatment was carried out using Microsoft Excel software.

\section{RESULTS AND DISCUSSION}

Biowaiver criteria for drugs containing BCS Class I active pharmaceutical ingredients (1) are:

1. The dosage form is rapidly dissolving (dissolution amount is greater than $85 \%$ at 30 min in all media with $\mathrm{pH} 1.2,4.5,6.8)$ and the dissolution profile of the test product is similar to that of the reference product in $\mathrm{pH} 1.2,4.5$, and 6.8 buffers using the paddle method at $75 \mathrm{rpm}$ or the basket method at $100 \mathrm{rpm}$ and meets the criteria of dissolution profile similarity, $f_{2} \geq 50$ (or equivalent statistical criterion);

2. If both the test and the reference dosage forms are very rapidly dissolving (dissolution amount is greater than $85 \%$ at 15 min in all media with $\mathrm{pH} 1.2,4.5,6.8$ ) the two products are deemed equivalent, and a profile comparison is not necessary.

Both evaluated drugs were "rapidly dissolving" (see Table 1) because the active pharmaceutical ingredient release at time point 30 min was more than $85 \%$.

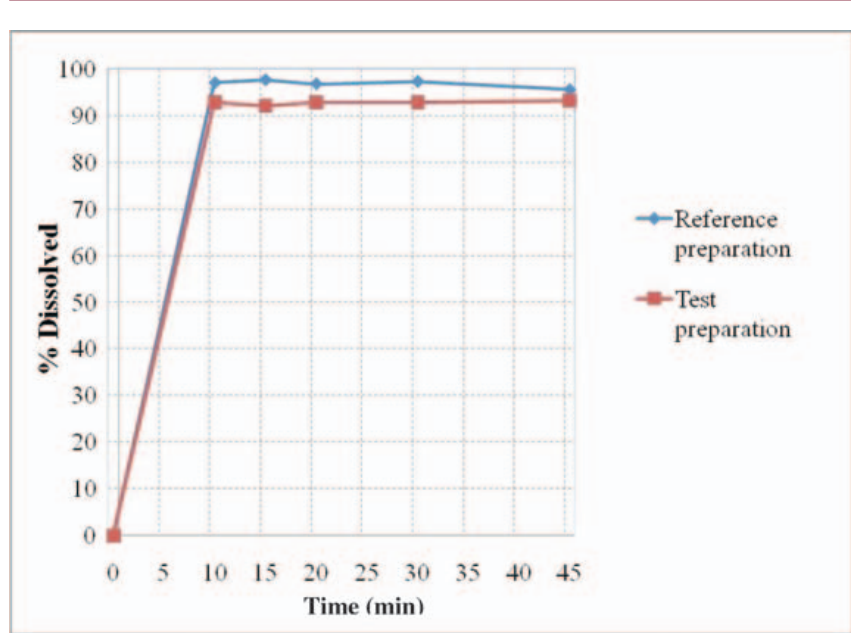

Figure 2. Dissolution profiles of test and reference drugs at $\mathrm{pH}$ 1.2.

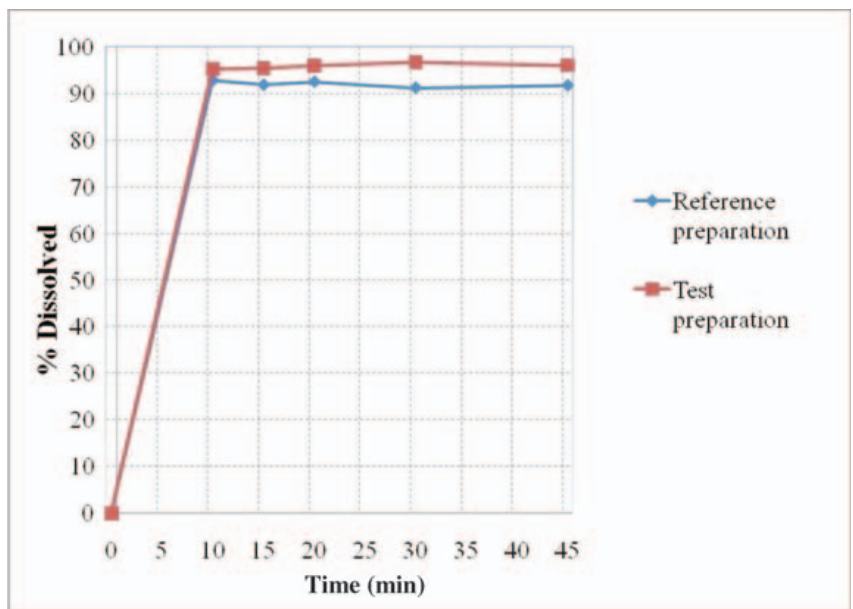

Figure 3. Dissolution profiles of test and reference drugs at $\mathrm{pH} 4.5$.

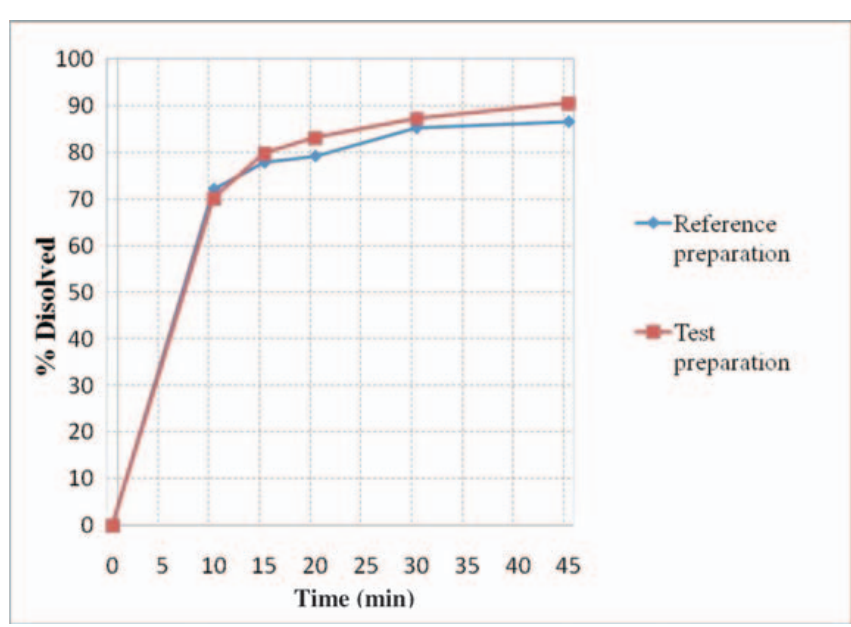

Figure 4. Dissolution profiles of test and reference drugs at $\mathrm{pH} 6.8$.

Dissolution Technologies | AUGUST 2010 


\begin{tabular}{|c|c|c|c|c|c|}
\hline \multirow[b]{2}{*}{ Medium } & \multirow[b]{2}{*}{$\begin{array}{l}\text { Time } \\
\text { (min) }\end{array}$} & \multicolumn{2}{|c|}{ Test Product } & \multicolumn{2}{|c|}{ Reference Product } \\
\hline & & $\begin{array}{c}\text { \% dissolved } \\
(\bar{X})\end{array}$ & RSD (\%) & $\begin{array}{c}\text { \% dissolved } \\
(\bar{X})\end{array}$ & RSD (\%) \\
\hline \multirow[t]{5}{*}{ pH 1.2} & 10 & 92.76 & 2.76 & 97.11 & 3.30 \\
\hline & 15 & 91.99 & 3.32 & 97.70 & 3.28 \\
\hline & 20 & 92.74 & 2.00 & 96.85 & 3.23 \\
\hline & 30 & 92.72 & 3.05 & 97.36 & 3.91 \\
\hline & 45 & 93.18 & 2.77 & 95.60 & 3.35 \\
\hline \multirow[t]{5}{*}{$\mathrm{pH} 4.5$} & 10 & 95.18 & 2.18 & 92.89 & 4.34 \\
\hline & 15 & 95.41 & 2.28 & 91.91 & 2.41 \\
\hline & 20 & 96.02 & 3.14 & 92.59 & 2.23 \\
\hline & 30 & 96.75 & 2.10 & 91.30 & 1.49 \\
\hline & 45 & 96.04 & 2.51 & 91.81 & 1.60 \\
\hline \multirow[t]{5}{*}{$\mathrm{pH} 6.8$} & 10 & 70.08 & 3.38 & 72.19 & 3.67 \\
\hline & 15 & 79.76 & 4.71 & 77.85 & 6.00 \\
\hline & 20 & 83.11 & 3.37 & 79.20 & 3.85 \\
\hline & 30 & 87.28 & 3.63 & 85.42 & 3.18 \\
\hline & 45 & 90.53 & 3.36 & 86.57 & 2.87 \\
\hline
\end{tabular}

Dissolution profiles and corresponding data are shown in Figures 2-4 and Table 2. Dissolution profiles in $\mathrm{pH} 1.2$ and 4.5 buffers were similar without statistical treatment (more than $85 \%$ released after $15 \mathrm{~min}$ ). For pH 6.8, the similarity factor $f_{2}$ value was 68 . Therefore, dissolution profiles of the test product are similar to those of the reference product at $\mathrm{pH} 1.2,4.5$, and 6.8 .

The percent relative standard deviation (\% RSD) for all time points fulfills all requirements ( $\leq 20 \%$ for $15 \mathrm{~min}$, $\leq 10 \%$ for other time points), so results are valid (see Table 2).

\section{CONCLUSION}

The evaluated amlodipine drugs fulfill biowaiver criteria for drugs containing BCS Class I active pharmaceutical ingredients. Both drugs are "rapidly dissolving," both meet the criteria of dissolution profile similarity, $f_{2}$ (i.e., the dissolution profile of the test product is similar to that of the reference product in $\mathrm{pH} 1.2,4.5$, and 6.8 buffers using the paddle method at $75 \mathrm{rpm}$ ), and both are considered to be in vitro equivalent without in vivo evaluation.

\section{REFERENCES}

1. WHO Expert Committee on Specifications for Pharmaceutical Preparations. WHO Technical Report Series, No. 937, Annex 8. Proposal to waive in vivo bioequivalence requirements for WHO Model List of Essential Medicines immediate-release, solid oral dosage forms; World Health Organization: Geneva, Switzerland, 2006.

2. Amlodipine besylate prescribing information, Pfizer, 2006.

3. United States Pharmacopeia and National Formulary USP 29-NF 24; The United Pharmacopeial Convention, Inc.: Rockville, MD, 2006.

4. European Pharmacopoeia, 6th ed.; European Directorate for the Quality of Medicines, Council of Europe:Strasbourg, France, 2007.

5. Drug Bank database. Drug card for Amlodipine. http:// www.drugbank.ca/drugs/DB00381 (accessed Jul 7, 2010) .

6. WHO Expert Committee on Specifications for Pharmaceutical Preparations. WHO Model List of Essential Medicines, 15th list; World Health Organization: Geneva, Switzerland, 2007.

7. FGU NCESMP Roszdravnadzor database. http://www. regmed.ru (accessed Jul 12, 2010). 